Proceedings

\title{
Experiences of Inclusive Teaching of Graphic Expression in the Context of Mechanical Engineering ${ }^{\dagger}$
}

\author{
Carlos Casqueiro *, Mercedes Solla, Xavier Núñez-Nieto and Rafael Carreño \\ Defense College, Spanish Naval Academy, Plaza de España, s/n, 36920 Marin, Spain; \\ merchisolla@cud.uvigo.es (M.S.); xnnieto@cud.uvigo.es (X.N.-N.); rafaelm@cud.uvigo.es (R.C.) \\ * Correspondence: ccasqueiro@cud.uvigo.es; Tel.: +34-986-804-935 \\ + Presented at the 2nd Innovative and Creative Education and Teaching International Conference \\ (ICETIC2018), Badajoz, Spain, 20-22 June 2018.
}

Published: 21 November 2018

\begin{abstract}
Some subjects of Engineering Mechanical result particularly difficult because previous knowledge and skills are required. It is the case of Graphic Expression. There are two main reasons justifying failure. Firstly, it is very common to find students with difficulties for the spatial vision. Secondly, a variable percentage of students do not have any previous experience about the contents of this subject since it is a non-compulsory subject in secondary school. This work presents different experiences of inclusive teaching to help these students to achieve the required level of knowledge and the evaluation of this activities.
\end{abstract}

Keywords: inclusive teaching; teaching and learning experiences; Graphic Expression; European Higher Education Area

\section{Introduction}

The teaching of Graphic Expression in a Mechanical Engineering degree poses different challenges mainly due to the high level of demand in relation to spatial vision comprehension and ability [1]. Spatial visualization was described as one of the eight human intelligences [2] and it is essential to achieve mental transformations when converting a 3D reality into a 2D representation [3] as needed in Graphic Expression. Spatial visualization has been related with the personal abilities and some studies have indicated the difficulties to teach the concept [3] but also the possibility of being improved through instruction [3-5]. Then, spatial visualization capabilities depend on the individual but also their experience and previous instruction.

In addition, the spatial visualization development has been linked to math skills [6] and engineering [7]. This way, deficiencies associated with spatial visualization could affect not only the learning of this subject, but also the success of many other subjects in an engineering degree.

However, at high school in Spain, subjects which includes these skills are non-compulsory for students to access to technical studies at university. These students usually present singular difficulties in learning and inclusive learning activities are therefore recommended to help them.

This work was developed in the Defense College (Centro Universitario de la Defensa-CUD) integrated in the Spanish Naval Academy to train future Spanish Navy officers in a Mechanical Engineering degree integrated into the European Higher Education Area (EHEA).

In last years, the number of students who access without previous knowledge in Graphic Expression at the CUD reached about $24 \%$. The academic achievements of this group of students were poorer than the ones acquired by the students with previous experience. In this frame, the teachers of the subject have become aware of the need to develop teaching-learning strategies to assist and improve the academic performance of students with severe deficiencies, as recommended 
by European Commission [8]. In application of the principles of the Bologna Declaration and the EHEA, this learning process will be understood as a continuous process embedded in a continuous evaluation system.

\section{Materials and Methods}

The study presented in this work was focused on two different approaches: design and application of inclusive learning activities and evaluation of their success. The different activities planned by the teachers in order to evaluate the level of knowledge of the students and to improve their comprehension and ability are described below:

1. Level test, to assess prior knowledge and abilities of the students to identify the differences in knowledge and the poorest capabilities, which allows us to define the learning activities with precision.

2. Zero course, to introduce briefly the most important basic concepts required to face the subject in good conditions. It is usually carried out in the first weeks of the term.

3. Group work task: the project. Students, whether or not they have knowledge or previous experience, work by groups in the elaboration of a document that includes a brief introduction and, mainly, the plans (2D standard views and perspectives like axonometric system) of a simple machine and its parts (Figure 1). Then, each student must present the results and his contribution to teachers and classmates.

Overview Drawing

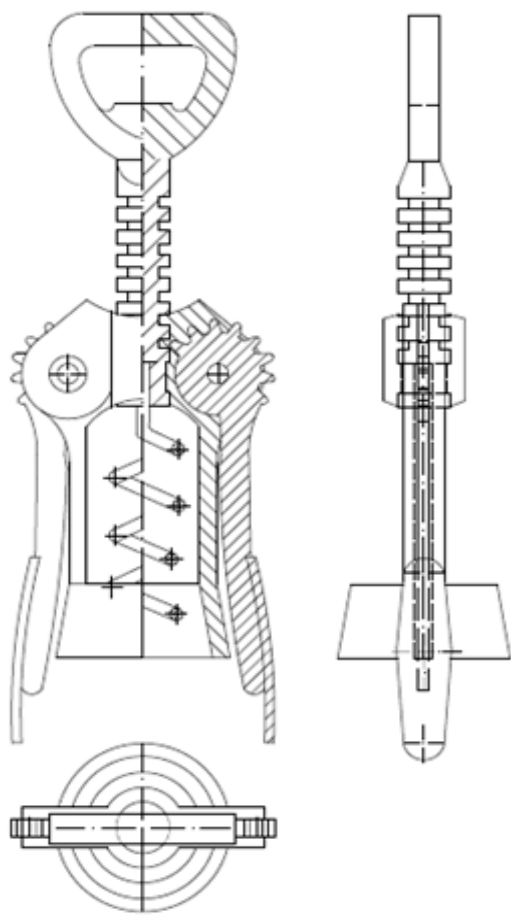

Partial Views

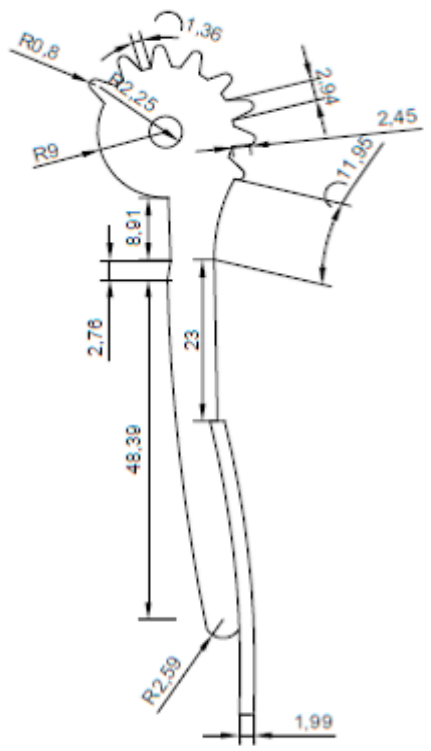

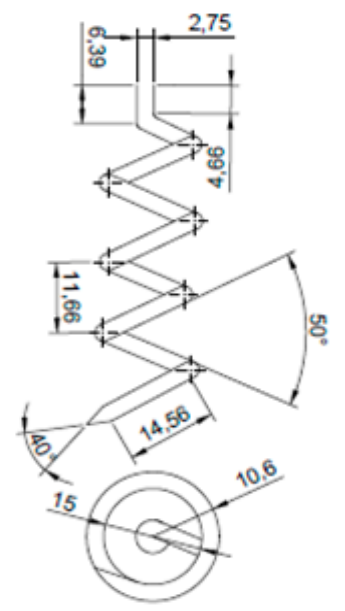

Figure 1. Example of different views elaborated in a project.

4. 3D printer for improving spatial visualization. Task of converting a 3D part into several 2D views (Figure 2), helped for versions of these parts sectioned in different ways to achieve a better understanding. These sectioned parts can be obtained from the original part by 3D printer and the students can measure the different details easier than over the original. It is possible to consider this and previous tasks like inclusive activities (except the zero course) because the students work together adapting the learning tool to their needs. 

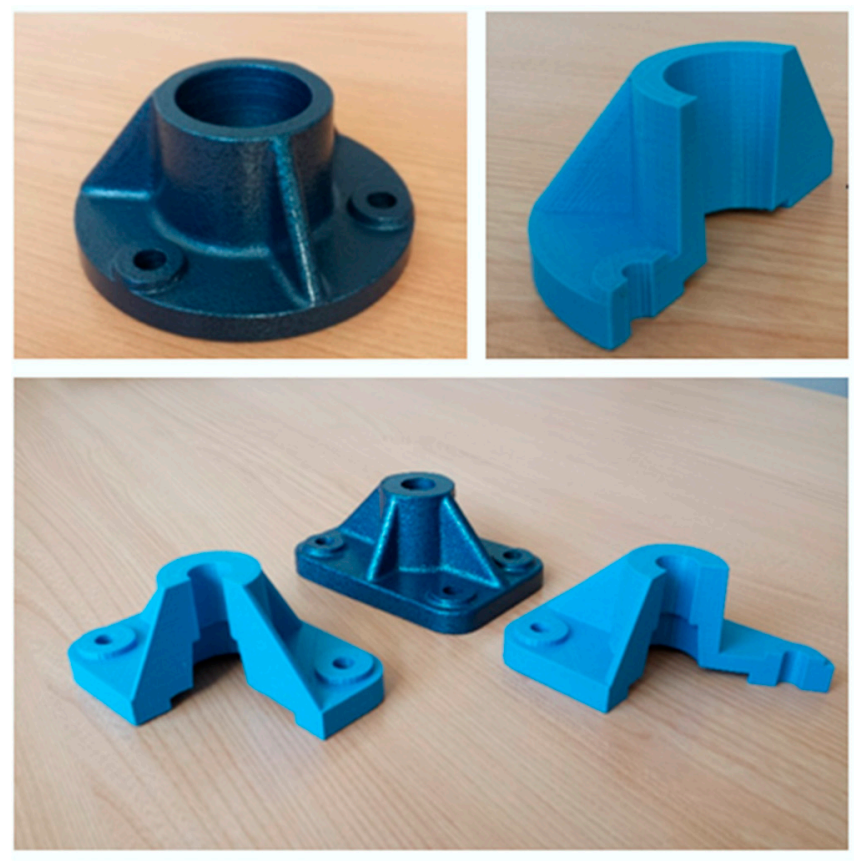

Figure 2. Example of sectioned printed parts and a drawing plan elaborated.

5. Partial and final exams and other assessments, required to grade students, but useful to know the effectiveness of the teaching-learning methodologies employed.

6. Satisfaction surveys to know the success and level of satisfaction of the students with the inclusive activities planned to help them with learning. Two surveys, one about the satisfaction with the group work project and the other one about the 3D printer activity, were done. The level of satisfaction was measured using a Likert rating scale, from 1 to 5 points, being the 1 for "nothing" and the 5 for "complete".

\section{Results and Discussion}

Two types of results are presented: the results obtained by students (separated whether or not the students have previous experience) through the different assessments and the results obtained from the satisfaction surveys realized to the students regarding the inclusive activities.

\subsection{Level Test}

Results of level test shown:

- Any student without previous experience passed the level test. The best mark obtained by this group of students was lower than 3 points (scored over 10).

- $58 \%$ of the students with previous experience passed the level test.

- $31 \%$ of the students with previous experience who did not pass the test obtained a mark between 4 and 5 points.

- The most difficult content, for students with previous experience, is dihedral system.

From the results obtained, it was possible to highlight the different level of knowledge and skills between the two groups of students (with and without previous experience), and students without experience seem will have special difficulties to learning.

\subsection{Exam Tasks and Results}

Figure 3 shows the success rate (separated by students with and without previous experience) for the different exams planned, including all the contents of the subject: level test (LT), continuous evaluation (CE), ordinary evaluation (OE) and the final rate in the first round (FR). 


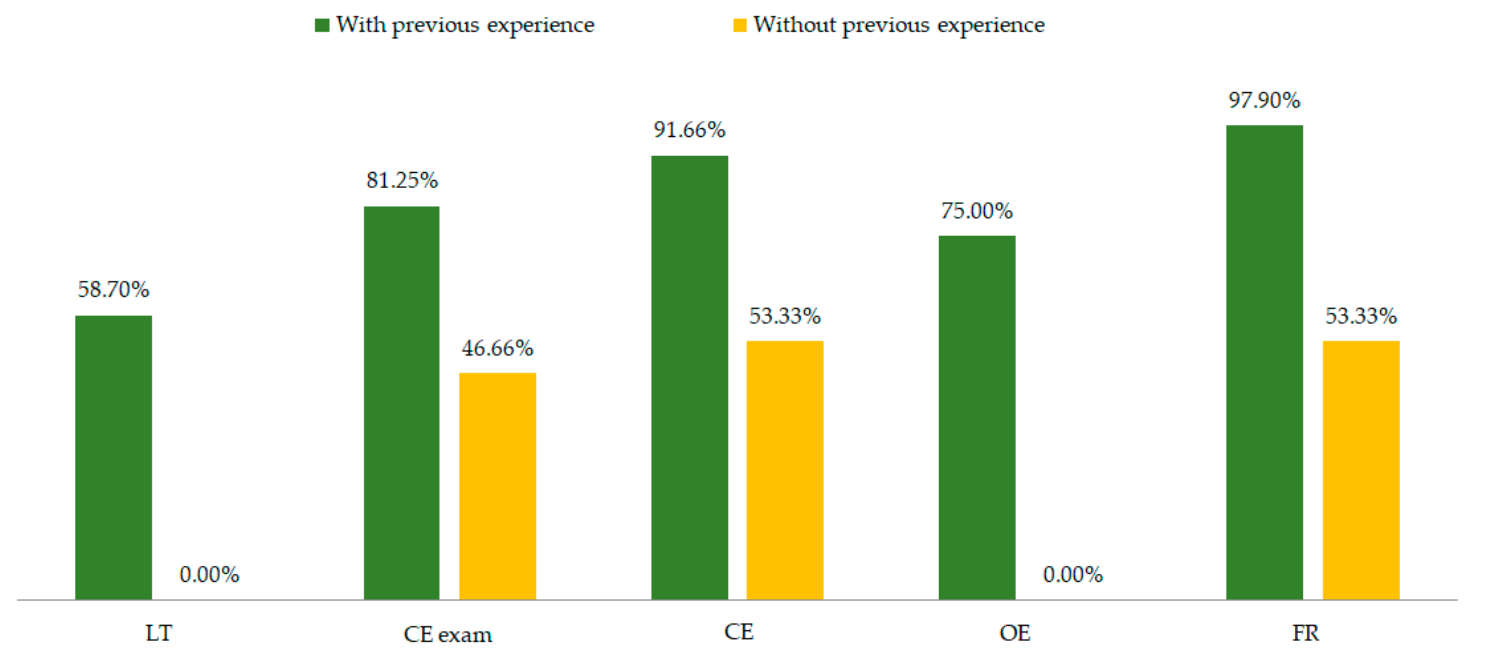

Figure 3. Compared results of different exams separated by students with and without previous experience.

All the students without previous experience failed the test level, but the final success of this group is more than a half of their classmates. Approximately $53 \%$ of the students without previous experience passed the continuous evaluation (CE), after enjoying the inclusive learning activities, versus $90 \%$ of the students with previous experience. This situation is not the same in Ordinary Exam. The students who did not passed the subject in continuous evaluation have to attend this exam, but they did not to take advantage of learning activities developed in the classroom.

\subsection{Satisfaction Surveys}

Table 1 describes the level of satisfaction by the students with respect to the group work and sectioned printed parts activities and the start situation of knowledge of students.

Table 1. Results of the satisfaction surveys about the group work and printed parts activity.

\begin{tabular}{lcc}
\hline \multicolumn{1}{c}{ Question } & $\begin{array}{c}\text { Students with } \\
\text { Previous Experience } \\
\text { (Scored over 5) }\end{array}$ & $\begin{array}{c}\text { Students without } \\
\text { Previous Experience } \\
\text { (Scored over 5) }\end{array}$ \\
\hline $\begin{array}{l}\text { What was your ability for spatial visualization and your } \\
\text { knowledge about standards of technical drawing before } \\
\text { starting this subject? }\end{array}$ & 3.6 & 1.3 \\
\hline $\begin{array}{l}\text { How many important was the realization of the project } \\
\text { (group work) to improve your knowledge of standards } \\
\text { in drawing? }\end{array}$ & 3.1 & 3.2 \\
\hline $\begin{array}{l}\text { Grade the utility of the project-based learning in } \\
\text { comparison with traditional learning methods. }\end{array}$ & 3.1 & 3.1 \\
\hline $\begin{array}{l}\text { Grade the contribution of the activity to the group work } \\
\text { competence. }\end{array}$ & 3.5 & 3.9 \\
\hline $\begin{array}{l}\text { Grade the utility of the seminar of standard views using } \\
\text { 3D printed to improve your spatial visualization abilities. }\end{array}$ & 3.3 & 3.9 \\
\hline
\end{tabular}

Both activities were graded with medium-high scores and the level of satisfaction was similar in both groups of students considered (with and without previous experience) Nevertheless, the students without experience gave a higher score to the contribution of the activity to the group work competence (3.9 versus 3.5), which certainly demonstrates that this group of students more widely recognized the collaborative work as a learning methodology. With respect to the level of satisfaction with the 3D printed parts activity, the group of students who had spatial visualization difficulties considered the activity of greater utility than the other group (3.9 and 3.3 over 5, respectively). 


\section{Conclusions}

After this study, it was possible to conclude that the students without previous experience related to Graphic Expression or Technical Drawing had more difficulties to pass the subject as expected. However, the inclusive activities planned in order to assist and improve the learning process and academic results of those students presenting difficulties have demonstrated positive effects.

For further improvements in the teaching-learning methodology, inclusive activities should be designed and implemented focused on the contents of the geometry block, and more particularly on the dihedral system.

Author Contributions: C.C., M.S., X.N. and R.C. are the teachers of the subject and they conceived and designed the different inclusive activities performed; C.C. and M.S. analyzed the data and wrote the paper.

Acknowledgments: The Defense College and the Spanish Naval Academy are acknowledged for the facilities and human resources that made this research possible.

Conflicts of Interest: The authors declare no conflict of interest. The founding sponsors had no role in the design of the study; in the collection, analyses, or interpretation of data; in the writing of the manuscript, and in the decision to publish the results.

\section{References}

1. Álvarez-Caldas, C.; Quesada, A.; Calvo, J.A.; San Román, J.L. Aplicación interactiva para la docencia de los fundamentos del sistema diédrico. In Proceedings of the Congreso Ibero-Americano de Ingeniería Mecánica (CIBEM), Porto, Portugal, 4-7 September 2011; Natal Jorge, R.M., Tavares, J.M.R.S., Alexandre, J.L., Ferreira, A.J.M., Vaz, M., Eds.; Facultade de Engenheria da Universidade de Porto: Porto, Portugal, 2011.

2. Gardner, H. Frames of Mind: The Theory of Multiple Intelligences, 3rd ed.; Basic books: New York, NY, USA, 2011.

3. Strong, S.; Smith, R. Fundamentals and Trends in Engineering Graphics. J. Ind. Technol. 2001, 18. Available online: https://cdn.ymaws.com/www.atmae.org/resource/resmgr/JIT/strong122001.pdf (accessed on 25 May 2018).

4. Mataix San Juán, J. La Habilidad Espacial en los Estudiantes de Carreras Técnicas. Desarrollo, Medida y Evaluación en el Marco del Espacio Europeo de Educación Superior. Ph.D. Thesis, Universidad de Córdoba, Córdoba, Spain, 2014.

5. Burnett, S.A.; Lane, D.M. Effects of academic instruction on spatial visualization. Intelligence 1980, 4, 233242, doi:10.1016/0160-2896(80)90021-5. Available online: http://www.sciencedirect.com/science/article/pii/0160289680900215 (accessed on 25 May 2018).

6. Mix, K.S.; Cheng, Y.L. The Relation between Space and Math. Developmental and Educational Implications. Adv. Child Dev. Behav. 2012, 42, 197-243, doi:10.1016/B978-0-12-394388-0.00006-X.

7. Saorín-Pérez, J.L.; Navarro-trujillo, J.L.; Martín-Dorta, N.; Martín-Gutierrez, J.; Contero, M. La capacidad especial y su relación con la ingeniería. DYNA Ing. Ind. 2009, 84, 731-732.

8. European Commission, Directorate General for Education and Culture. (Ed.) Education and Training in EUROPE: Diverse Systems, Shared Goals for 2010; The work programme on the future objectives of education and training systems; European Commission, Directorate General for Education and Culture: Brussel, Belgium, 2002.

(C) 2018 by the authors. Licensee MDPI, Basel, Switzerland. This article is an open access article distributed under the terms and conditions of the Creative Commons Attribution (CC BY) license (http://creativecommons.org/licenses/by/4.0/). 